\title{
The Interplay between Text-based Vocabulary Size and Reading Comprehension of Turkish EFL Learners
}

\author{
Fatih Güngör ${ }^{1}$ \\ Afyon Kocatepe University
}

\author{
Demet Yayll ${ }^{2}$ \\ Pamukkale University
}

\begin{abstract}
Reading is an indispensable skill for learners who desire success throughout their academic lives, and vocabulary knowledge is a sine qua non companion of reading comprehension. Despite being inextricably related entities, very little has been written about the necessary vocabulary coverage to understand an expository text and its equivalent in terms of vocabulary size in Turkish EFL context. Therefore, with this study, we focused on the relationship between the vocabulary coverage and reading comprehension of a group of foreign language learners. For this study, 178 university students completed a vocabulary checklist based on the vocabulary items of two different expository texts, and their reading comprehension levels were measured through two piloted reading comprehension tests for each text. The descriptive statistics, Pearson's correlation value and regression analysis were employed to analyze the data. The results revealed that the text-based vocabulary knowledge moderately correlated with reading comprehension, and there was a relatively linear relationship between them. It was also concluded that the $98 \%$ vocabulary coverage is needed for foreign language learners to comprehend academic texts, and this coverage, in fact, refers to approximately the most frequent 8000 word-families based on the related studies.
\end{abstract}

Keywords

Vocabulary coverage $\bullet$ Vocabulary size $\bullet$ Reading comprehension $\bullet$ Turkish EFL learners $\bullet$ Academic vocabulary

\footnotetext{
* This study was prepared based on the master's dissertation of the corresponding author.

1 Correspondence to: Fatih Güngör, English Language Teaching Program, Department of Foreign Languages Education, Faculty of Education, Afyon Kocatepe University, Afyonkarahisar 03200 Turkey. Email: fgungor@aku.edu.tr

2 Department of Foreign Languages Education, Pamukkale University, Denizli 20070 Turkey. Email: demety@pau.edu.tr

Citation: Güngör, F., \& Yaylı, D. (2016). The interplay between text-based vocabulary size and reading comprehension of Turkish EFL learners. Educational Sciences: Theory \& Practice, 16, 1171-1188.
} 
Recently, there has been a burgeoning interest in the relationship between reading comprehension and vocabulary knowledge, and this emanates from the fact that academic achievement is closely related to reading performance (Adamson, 1993; Collier, 1989). As might be expected, the best way to learn new vocabulary items is considered to read, and knowing extensive vocabulary is a prerequisite to understand a text (Eskey, 2005). Therefore, it is necessary to scrutinize breadth of a person's vocabulary as a predictor of reading comprehension on a regular basis to reach a consensus about the amount of vocabulary needed by an L2 learner for a reasonable comprehension of expository texts. However, although there have been several studies evaluating the relationship between reading comprehension and vocabulary knowledge in general, these studies do not include Turkish learners of English as participants whose native language is not etymologically related to English. Scholars, on the other hand, acknowledge that English as a foreign language (EFL) learners feel the burden of reading in an L2 twice as much as their counterparts, L1 readers, do, and success is difficult to come by without being a skilled reader (Carrell \& Grabe, 2002). For that reason, the present article aims to investigate a perennial concern, that is, the relationship between the vocabulary coverage and reading comprehension of a group of Turkish EFL learners because first reading is an indispensable skill for academic achievement and second reading comprehension is directly linked to learners' vocabulary knowledge. After a brief summary about reading comprehension and vocabulary knowledge as a reciprocal process, the article aims to discuss what percent of the vocabulary items should be known in an expository text to comprehend it, and the corresponding vocabulary size will be discussed by analyzing the sizes suggested in the studies of Nation (2006), and Laufer and Ravenhorst-Kalovski (2010).

\section{A Reciprocal Process: Reading Comprehension and Vocabulary Size}

Reading is delineated as "the process of receiving and interpreting information encoded in language form via the medium of print" (Urquhart \& Weir, 1998, p. 22). As stated by Linan-Thompson and Vaughn (2007), and Grabe and Stoller (2002), reading comprehension is the main purpose for reading, and this purpose underlies and supports most of the other purposes for reading. However, since reading involves cognitive processes, reading comprehension is an invisible concept that can only be inferred (Bernhardt, 2011). Moreover, reading comprehension presents some challenges for learners as many students consider reading a boring and difficult task. When the complexity of reading is considered together with its purposes and properties, it becomes clear that reading is complex for both teaching and learning.

In addition to the complexity of reading, it is unarguably clear that the relationship between vocabulary size and reading comprehension is reciprocal. While some scholars focus on the effects of vocabulary size on reading comprehension in their studies, some 
others study the effects of reading comprehension on vocabulary size (Eskey, 2005; Hu \& Nation, 2000; Nation, 2001; Nation \& Angell, 2006). According to Rumelhart (1977) and Stanovich (1980), in evidence-based reading models, bottom-up processes such as word recognition and lexical access go hand in hand with top-down processes such as integrating background knowledge and processing strategies. Readers need automaticity in both word recognition and lexical access (Walter, 2003). From a lexical perspective, Anderson (2009) and DeKeyser (2007) summarize this long learning process as a path from understanding a word's meaning to learning a major meaning of a word, and then learning many aspects of a word's meaning and use. Therefore, the faster a reader recognizes a word, which is linked to learners' vocabulary knowledge and automaticity, the better reading comprehension will take place.

Based on these two complex but inextricably related concepts, the studies conducted by researchers can be helpful to understand the relationship between the variables that might lead to a consensus about the necessary vocabulary size to comprehend an expository text. As stated earlier, some studies focus on the effects of vocabulary size on reading comprehension while others study the effects of reading comprehension on vocabulary growth. However, vocabulary size, in the present study, is seen as the predictor of reading comprehension, and the effects of vocabulary coverage on reading comprehension are scrutinized within an EFL context. Although it is possible to observe many findings about vocabulary as a predictor of early reading achievement in first language (L1) settings (Bowey, 1995; Caravolas, Hulme, \& Snowling, 2001; Stanovich, 1986, 2000; Thorndike, 1973), there are not many studies conducted in second language (L2) settings.

In one of the earliest studies, Laufer (1989) aimed to measure the relationship between the number of English words understood by a reader in an academic text written in English and the quality of comprehension of the text with native Hebrew and Arabic speakers. The 101 first year students who were taking a course of English for academic purposes were assigned to answer comprehension questions and to underline the words they could not understand in the text. As the result of the study, the group which scored $95 \%$ and above in lexical coverage test scored better in the reading comprehension test than the groups which scored $90-94 \%$ and $89 \%$ and below. In other words, Laufer supports the threshold hypothesis in reading comprehension, and suggests that $95 \%$ and above lexical coverage of the text is necessary.

In another study, for example, Nation (2006) and Laufer and RavenhorstKalovski (2010) investigated which vocabulary level provides sufficient reading comprehension. Both studies focused on the hypothesis that $98 \%$ vocabulary coverage would be needed for necessary comprehension; however, Nation used a computer program to find a threshold level while Laufer and Ravenhorst-Kalovski 
conducted the study with 735 students who studied in academic college in Israel, and took an English for academic purposes course. In sum, Nation's and Laufer and Ravenhorst-Kalovski's studies gave nearly same vocabulary size which is on average $7000-8000$ plus proper nouns to reach $98 \%$ coverage level in academic texts.

On a similar basis, Hu and Nation (2000) aimed to see what percentage of coverage in a text was needed for reading for pleasure. The correct answers to the comprehension questions were compared to a vocabulary levels test scores of 66 adult English as a Second Language (ESL) learners who were attending a preuniversity English course in an English speaking country. The mother tongues of the participants were Thai, Chinese, Ni-Vanuatu, Indonesian, Japanese, Korean, Vietnamese and German. Different densities of unknown words resulted in differences in comprehension, which was observed through the answers given to the questions of a fictitious text. Also, the hypothesis that the comprehension declined as the number of unknown words increased was confirmed. Although Hu and Nation (2000) conducted the study to measure adequate comprehension in fictitious texts, they found that the same percentage, $98 \%$ coverage, was needed for most learners to gain adequate comprehension.

Up to this point, the previous studies investigated the relationship between reading comprehension and vocabulary size with vocabulary size tests; however, Schmitt, Jiang, and Grabe (2011) investigated the relationship on the basis of the exact number of the words known in a text. In their study, 661 students from eight different countries answered an extended vocabulary checklist test and a reading comprehension test. Although a moderate correlation was found between the variables, they could not identify a threshold on which comprehension increases greatly. For the vocabulary coverage, Schmitt et al. (2011) concluded that 98\%-99\% coverage is required for understanding an expository text but having a deeper lexical knowledge does not mean that it would enhance the chances of comprehension to a greater extent.

One of the important limitations of the studies before the one by Schmitt et al. (2011) was that they analyzed the relationship between reading comprehension and vocabulary size with vocabulary tests; however, the results were inconclusive as the tests asked a few items because of limited time. With an extended checklist, Schmitt et al. removed this limitation to identify vocabulary size of the learners more appropriately. However, they did not analyze the learners' performances based on their first languages, and this handicap might have caused some fluctuations in the results as some learners could have been advantageous in terms of their first language. Considering the fact that the reading test scores of Turkish EFL learners are significantly under the average in TOEFL and IELTS (Educational Testing Service, 2012; IELTS, 2011), and given that there is an etymological distance between the 
two languages (i.e., Turkish is an Altaic language with an agglutinative morphology (Durrant, 2013) and English is an Indo-European language) it is of importance to scrutinize the relationship between vocabulary size and reading comprehension with Turkish students of English, as well. Since the participants shared the same L1 in this study, various L1s in this case did not have a fluctuating effect on the interpretation of the results. In sum, the following research questions were posed in the present study:

i. Is there a threshold level in terms of vocabulary coverage between adequate and inadequate comprehension of an academic text?

ii. Will different percentages of vocabulary coverage result in differences in reading comprehension? In particular, will comprehension increase as the number of vocabulary coverage increases?

iii. What percentage of coverage is necessary to comprehend an expository text at an adequate level?

\section{Method}

\section{Setting and Participants of the Study}

The respondents who took part in this study were enrolled in an English Language Teaching (ELT) program at a state university in Turkey. To be eligible for studying at undergraduate ELT programs in Turkey, students are required an English language test. This test is a component of the university entrance examination for the students who would like to study in language programs at universities in Turkey. In the current study, the undergraduate respondents, who passed the placement test or studied oneyear preparatory program, were selected as the participant group to determine the optimal vocabulary size that is necessary for comprehending expository texts. In sum, these participants were a group of ELT program students who study in this program for four years to be able to work at institutions of different levels (i.e., from primary level to tertiary level) as language teachers.

For the study, a vocabulary checklist and a reading comprehension test were distributed to a total of 184 students; however, 8 of the respondents were excluded since four of them marked more than three non-words, and two of them denied to answer more than half of the reading comprehension test battery. In this sense, the study group was comprised of 178 respondents, which was composed of 76 freshman, 60 sophomore, 40 junior, and 2 senior students. As for the gender distribution of the respondents, $71.3 \%(n=127)$ were females and $28.7 \%(n=51)$ were males. The respondents between the ages of 18 and 23 comprised approximately $90 \%$ of the study group. Even if the simple random sampling process was followed, the population was 
included in the same proportions in terms of gender as in stratified random sampling. In this sense, these numbers increased the likelihood of representativeness (Fraenkel, Wallen, \& Hyun, 2012).

\section{Data Collection Instruments}

Vocabulary checklist. In this study, we asked the participants to answer a vocabulary checklist after they filled in the informed consent form and demographic information part. The vocabulary checklist was used to measure vocabulary coverage of the students without violating the authenticity of the texts. Since checklist tests serve to measure a large number of words, $60.7 \%$ of the content words were measured in this study. In the vocabulary research, selecting the target lexical items is one of the basic and critical steps, and frequency is one of the most important aspects for selecting these lexical items (Schmitt, 2010). In this sense, the readings were submitted to BNC-20 v 3.2 British National Corpus lists version of VocabProfilers program (www.lextutor.ca) to determine the frequency levels of the vocabulary in the readings. It is possible to determine the first 20.000 frequent words in the BNC with the help of VocabProfilers program. Therefore, the readings used in the study were analyzed with the program, and a large proportion of the readings $(78.60 \%)$ were formed of K1 words which represented the first 1000 frequent words list in BNC. The percentage of K2, K3 and K4 words was $14.5 \%$. Off-list words, which may include proper nouns, unusual words, specialist vocabulary, acronyms and abbreviations, contributed $2.39 \%$ to the total. When we looked at the type-token ratio, which indicates the number of different words in the text (types) divided by the number of words on which they are based (tokens), the average was found as 0.44 . In other words, the lexical variety was measured as $44 \%$.

As a limitation of such checklists, the answers of the learners might not be reliable. To propose a solution for this problem, an automatic check was built in the test in order to ensure that the learners' self-assessments were reliable (Meara, 1992), and 22 plausible non-words from Meara and his friends' list were integrated into the sets of vocabulary items. In sum, a vocabulary checklist which was comprised of 168 words was used to measure the number of the words the students knew. This 168word checklist gave an advantage to check 290 words practically in a short time.

Reading texts and comprehension tests. Following this checklist, a reading comprehension test was given to students in order to measure their reading comprehension level. Three criteria were considered in the text selection process: student factors (Frantzen, 2003; Levine \& Reves, 1998), text factor (Hu \& Nation, 2000), and context factors (Diakidoy \& Anderson, 1991; Frantzen, 2003; Haastrup, 1991). As the study group was comprised of the university students, two expository texts which could serve as an archetype for more thorough descriptions of a variety 
of scientific genres (Lewin, Fine, \& Young, 2001) were chosen from the Science and Technology part of The Economist. The Research \& Development in AmericaBad Medicine was printed on March 2 ${ }^{\text {nd }}$, 2013, and the Exercise and Elderly- Circuit Training appeared on September 22 $2^{\text {nd }}, 2005$. The lengths of the texts were 545 and 578 words respectively. The difficulty analysis was carried out based on the Flesch-Kincaid Grade Level. The Flesch-Kincaid Grade Levels were 8.7 and 9.3 for these two texts which have been roughly "the norm in much past reading research, in order to mimic the more extended reading of the real world" (Schmitt et al., 2011, p. 30). Considering the contextual factors and the profile of the participants, the first reading test and its test battery of Schmitt et al. (2011) were excluded, and a new test battery was developed for The Research \& Development in America- Bad Medicine by the researchers.

To eschew the limitations of the study and increase the content validity, the first test battery of the Exercise and Elderly- Circuit Training was adapted from the study of Schmitt et al. (2011) with their permission and taken as a basis since they, as the well-known experts in the field of L2 reading, used multiple methods and techniques to measure the comprehension level of students (Alderson, 2000; Alderson, Clapham, $\&$ Wall, 1995) and piloted the test battery twice in different contexts. Considering the fact that their study aimed to analyze the relationship between vocabulary size and reading comprehension, they included the questions to assess the vocabulary knowledge of the participants but avoided to ask vocabulary items directly. The second test battery was prepared in line with the aims of the first test battery, and it included similar questions in tune with the first test battery. For each text, 10 multiplechoice (MC) questions and 10 graphic organizer (GO) questions were prepared and incorporated. As put forward by Haladyna (2004), MC questions are efficient and provide a useful summary of student learning of knowledge and cognitive skills, especially for large-scale testing programs. As the second part, GOs were used as a frequently used information transfer task. The respondents were expected to transfer the information from the text to the graphic organizer. Alderson et al. (1995) emphasize GOs as information transfer tasks which resemble real-life activities. The drawback for the GOs is the objectivity of marking. To overcome this drawback, two scorers marked the GOs of the first 30 respondents in line with the answer sheet. The marks that two scorers yielded were consistent; however, an analytical scoring instrument was prepared to increase inter-rater and intra-rater reliability of the results (Brown, 2003). The rest of the papers were scored by the researcher.

As the novelty of the study, the comprehension questions were written in Turkish, the first language (L1) of the respondents. In the literature, in Turkey, a study using L1 as the medium of comprehension questions could not be found. Many authors such as Figueroa and Hernandez (2000) stress the potential harm embedded in the sole use of L2 while assessing comprehension. Therefore, native language assessment 
forms are seen as the most effective type by some researchers (Lara \& August, 1996). According to Nation (2009), the questions in the first language could be worth using if learners feel comfortable with them. In line with the views of Nation and some other researchers, we gave a set of Turkish comprehension questions to the respondents with an attempt to fill in the gap in the field. The details of the piloting study were given in the following section.

\section{Piloting Study}

Language testers are frequently reminded that the qualities of reliability and validity are essentially in conflict, and it is not easy to design test tasks that are authentic and at the same time reliable (Bachman \& Palmer, 1996). Nevertheless, it does not mean that one of these can be ignored in test designing process. For the test battery, the question set of "Circuit Training" was adapted from the study of Schmitt et al. (2011) with their permission, and 10 MC questions and 10 GOs were written for the other text entitled "Bad Medicine". . The content validity of the test batteries was reviewed by the second researcher of the current study as the advisor of the dissertation and an expert in the field. The other professors' opinions were also consulted. Besides, the texts and the questions were read by a group of English instructors to ascertain the readability and intelligibility to avoid misunderstandings. After all these processes, the pilot study was conducted at an ELT program of Gazi University, Turkey. The piloting population was 136, and the numbers of the female and male respondents were 116 and 19 respectively. The most frequent method employed for internal consistency of the test items is Kuder-Richardson approach, particularly formulas KR20 and KR21 (Fraenkel et al., 2012). The KR20 reliability estimates for the reading tests were as follows: 0.72 for the entire reading test, 0.70 for "Bad Medicine" and 0.60 for "Circuit Training". The value of 0.70 is a desirable level for the reliability, and the reliability level can be considered as moderate. To have a detailed look, the complete test battery was given to two language experts in Turkish language who did not observe any flaws linguistically. Consequently, the same version of the reading test was decided to be used in the study.

\section{Data Collection and Analysis}

In addition to descriptive statistics, Pearson's correlation value and regression analysis were employed to analyze the data. Descriptive statistics are a good way to get a snapshot of the distribution of the data. To analyze the relationship between the vocabulary coverage and reading comprehension, Pearson's product-moment correlation coefficient was used as an example of the bivariate correlation. After the correlation analysis, we did a simple regression analysis to predict an outcome variable from one predictor variable (Field, 2009). Hereby, the predictor variable 
was the vocabulary coverage of the respondents, and the outcome variable was the achievement of the respondents in the reading comprehension tests.

\section{Results}

\section{Descriptive Statistics}

As given in the method part of the study, there were 168 words in the vocabulary checklist. However, the first 35 words from the K1 list represented 158 vocabulary items. Therefore, the number of the known words was multiplied by 158 and divided by 35 to find the approximate number of the known words in the total of 158 words in K1 list. Thus, the number of the words measured in the checklist was 290, and all statistical procedures were carried out based on this number of words. Based on the 290 words, the mean value for the whole checklist was computed as $238.3(82.17 \%)$ with a standard deviation of 18.83 . The values ranged from 179 to 279 , and the variance was found as 354.63 for the checklist. The mean for the K1 list was about 145 , and 11 students $(6.2 \%)$ knew all the 158 words in K1 list. The number of the students who knew $142(\sim 90 \%)$ or more words in K1 list was $135(75.9 \%)$. The mean value of the K2 list ( $\mathrm{m}=49.90)$ was also high, and 39 students $(21.9 \%)$ knew all words in K2 list. The number of the students who missed just one word was $38(21.35 \%)$. The number of the students who knew 48 (90\%) or more words was $145(81.46 \%)$.

In the first 5000 list, the students knew at least one word. However, there were some students (74 students for K6 list, 10 students for the K7 list and 22 students for the K8 list) who did not have an idea with the words in K6, K7 and K8 lists. Furthermore, we observed that students had difficulty in K10, K12, K14 and K16 levels, and, respectively, 166, 155, 159 and 163 students did not know even one word in these lists. According to the mean values of the first 8000 words, the students knew about $235(86.08 \%)$ out of 273 words in the checklist. Nation (2006) concludes that the English Language learners (ELLs) should know the first 8000 words to reach a level of $98 \%$ coverage for reading newspapers. Regarding the assumption of Nation (2006), the vocabulary coverage and comprehension level of the students could be analyzed in terms of correlation of the first 8000 words, too. In line with the results of current study, Kirmizi (2014) also revealed that the Turkish EFL learners at undergraduate English language and literature programs had a high level of vocabulary in K2, K3 and academic vocabulary list but a moderate level of vocabulary in K5 and a low level of vocabulary in K10 lists.

The mean value for the entire reading test was 22.36 (55.9\%) which can be interpreted as a little higher than 20, the half of the questions. The number of the right answers ranged from $7(17.5 \%)$ to $35(87.5 \%)$. According to these results, none of the participating students answered all the questions in the test battery right. The 
number of the right answers accounted for $87.5 \%$ of the entire test for the best student who answered 35 questions right. Considering the right answers of the different test types, the mean value of the right answered multiple-choice questions was 10.76, and the mean value of the right answered graphic organizer questions was 11.60. The standard deviations of MC and GO questions were 2.63 and 4.14 respectively. For the entire test, the standard deviation was 5.79.

\section{Interplay between Vocabulary Coverage and Reading Comprehension}

Based on the first research question of the study, we sought a threshold but could not find one according to the results in Table 1 and Table 2. At the level of $88 \%$ coverage, an increase was seen with the mean score of 26.50. After this percentage, the vocabulary coverage and text comprehension started to increase gradually. On the other hand, this increase mitigated at the levels of $90 \%, 92 \%$ and $96 \%$ coverage. Due to the flaws at these levels, there was not an obvious point at which comprehension would accelerate dramatically. The reason for this decrease might be the limited number of respondents who knew $96 \%$ and $92 \%$ of the content words in the text. Therefore, the first hypothesis of the study was eliminated since there were some flaws at some vocabulary coverage levels. The results of this study corroborates with the study of Schmitt et al. (2011) as they could not find a threshold at which comprehension increases sharply, either.

\begin{tabular}{|c|c|c|c|c|c|c|c|c|}
\hline \multicolumn{9}{|c|}{$\begin{array}{l}\text { Table } 1 \\
\text { The Vocabulary Coverage \& Reading Comprehension -1- }\end{array}$} \\
\hline & $96 \%$ & $94 \%$ & $95 \%$ & 9270 & $91 \%$ & $90 \%$ & 0970 & $00 \%$ \\
\hline Student Numbers & 1 & 3 & 3 & 1 & 3 & 6 & 11 & 4 \\
\hline Mean ${ }^{b}$ & 22.00 & 29.00 & 28.00 & 24.00 & 27.67 & 24.50 & 26.82 & 26.50 \\
\hline Median & 22.00 & 29.00 & 30.00 & 24.00 & 25.00 & 24.00 & 28.00 & 25.00 \\
\hline SD & - & 2.00 & 6.25 & - & 4.62 & 3.51 & 5.74 & 6.19 \\
\hline Min. & 22.00 & 27.00 & 21.00 & 24.00 & 25.00 & 20.00 & 15.00 & 21.00 \\
\hline Max. & 22.00 & 31.00 & 33.00 & 24.00 & 33.00 & 29.00 & 34.00 & 35.00 \\
\hline
\end{tabular}

Note. ${ }^{\mathrm{a}}$ Vocabulary coverage, ${ }^{\mathrm{b}}$ The mean scores of the 40 -question comprehension test.

Table 2

The Vocabulary Coverage \& Reading Comprehension -2-

\begin{tabular}{lcccccccc}
\hline & $87 \%^{\mathrm{a}}$ & $86 \%$ & $85 \%$ & $84 \%$ & $83 \%$ & $82 \%$ & $81 \%$ & $80 \%$ \\
\hline Student Numbers & 12 & 17 & 11 & 11 & 18 & 12 & 5 & 6 \\
Mean ${ }^{\mathrm{b}}$ & 24.33 & 23.94 & 20.55 & 24.09 & 21.67 & 22.08 & 21.40 & 20.50 \\
Median & 25.50 & 22.00 & 20.00 & 25.00 & 20.00 & 23.00 & 24.00 & 20.00 \\
SD & 5.19 & 6.32 & 4.93 & 5.68 & 4.43 & 6.32 & 6.43 & 5.58 \\
Min. & 12.00 & 11.00 & 9.00 & 15.00 & 15.00 & 9.00 & 14.00 & 14.00 \\
Max. & 30.00 & 34.00 & 27.00 & 32.00 & 29.00 & 31.00 & 27.00 & 30.00 \\
\hline
\end{tabular}

Note. ${ }^{\mathrm{a}}$ Vocabulary coverage, ${ }^{\mathrm{b}}$ The mean scores of the 40 -question comprehension test. 
The mean scores of the comprehension test gave an idea about what percentage of vocabulary is needed to understand a similar text. This level depends on the degree of required comprehension. This required degree of comprehension ranges from 55 to 70 in different studies (Laufer, 1989; Laufer \& Sim, 1985; Schmitt et al., 2011) based on the required pass marks of the courses. If this level is taken as $70,93 \%$ and $94 \%$ vocabulary coverages make texts comprehendible. However, it should not be ignored that the vocabulary coverage over $96 \%$ percent could not be represented in the study since there was no respondent over $96 \%$ vocabulary coverage. Therefore, the regression models made up for the lost data in this range, and gave the predictive results regarding the percentages over $96 \%$ in the following sections.

To shed light on the second research question of this study which is concerned with whether different percentages of vocabulary coverage result in differences in reading comprehension, Pearson's correlation coefficient was employed and found as $.41(n=178, p<.01)$. According to Cohen (1988), the values between .30 and .49 can be regarded as moderate correlation. The correlation coefficient indicated that the vocabulary coverage accounted for $17 \%$ of the variation in the reading comprehension level. In other words, this means that $83 \%$ of the variation could not be explained by the vocabulary coverage alone. This result exactly corroborates with the results in the study of Schmitt et al. (2011) $(r=.41)$.

\begin{tabular}{llllc}
\hline $\begin{array}{l}\text { Table } 3 \\
\text { Pearson Product-Moment }\end{array}$ & Correlations between The Variables \\
\hline \multicolumn{5}{l}{ Vocabulary Size } \\
Vocabulary Size & Pearson Correlation & 1.00 & Comprehension Test & \\
& Sig. (2-tailed) & & Sig. (2-tailed) & $.41^{* *}$ \\
& Pearson Correlation & $.41^{* *}$ & Pearson Correlation & 1.00 \\
Comprehension Test & Sig. (2-tailed) & .00 & Sig. (2-tailed) & \\
& 178 & & 178 & \\
\hline $\mathrm{N}$ & $* *$ Correlation is significant at the 0.01 level (2-tailed).
\end{tabular}

Furthermore, we sought a correlation between the vocabulary coverage for the first 8000 words and the reading comprehension level of the students. The reason for looking at for the first 8000 words in these expository texts was prompted by Nation's (2006) claim that it is the adequate quantity to read a newspaper. Hence, the source of the texts used in this study was also a well-known newspaper, the Economist. The Pearson's correlation coefficient value was $r=.44$, which means that there was a linear positive correlation between the vocabulary coverage for the first 8000 words and the reading comprehension level. The Pearson's correlation values of both analyses were also similar $\left(r_{1}=.41\right.$ and $\left.r_{2}=.44\right)$. Corroborating with the assumption of Nation (2006), vocabulary size accounted for 20 percent of variance 
in this study, as well. To interpret this value, the knowledge of the first 8000 words helped to explain about 20 percent of the variance in students' scores on the reading comprehension test. The 2-tailed significance was computed as .00 in this correlation.

In the literature, there is an agreement that vocabulary might not be the best but a good predictor of reading (Laufer, 1992; Laufer \& Ravenhorst-Kalovski, 2010; Nation, 2001). Schmitt (2011) found a moderate correlation $(r=.41, n=661, p<$ $.001)$ between the vocabulary coverage and reading comprehension, and this value is exactly the same as the one obtained in the analysis of the current study $(r=.41, n=$ $178, p<.001)$. In sum, the aforementioned studies point out that there are moderate and high correlations between vocabulary knowledge and reading comprehension no matter what the test types are. These results motivate studies on this relationship and lead researchers to delve into variables from different viewpoints.

\section{Optimal Vocabulary Coverage}

After checking all the assumptions such as normality of errors, histogram of standardized residuals and normal probability plot of the residuals, we carried out a regression analysis to answer the third research question. According to the regression analysis, the value of $\mathrm{B}_{1}$ is .125 and this value represented the gradient of the regression line. However, it is helpful to think of this value as representing the change in the reading comprehension level associated with a unit change in the vocabulary coverage. In other words, the model predicts that reading comprehension score increases about .125 for the one-word increase in the vocabulary coverage. For instance, the model predicts that a 10-word increase in the vocabulary size will enable to answer 1.25 questions more $(0.125 \times 10=1.25)$. Considering the value of significance level, .00 , it can be concluded that the vocabulary coverage made a significant contribution $(p<$ $.001)$ to predicting the reading comprehension level of the students.

\begin{tabular}{|c|c|c|c|c|c|}
\hline \multicolumn{6}{|c|}{$\begin{array}{l}\text { Table } 4 \\
\text { The Model Parameters and Significance of These Values }\end{array}$} \\
\hline Coefficients $^{\mathrm{a}}$ & 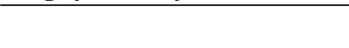 & & & & \\
\hline \multirow{2}{*}{ Model B } & Unstandardized Coefficients & Standardized Coefficients & & $t$ & Sig. \\
\hline & Std. Error & Beta & & & \\
\hline (Constant) & -7.47 & 5.06 & & -1.48 & .14 \\
\hline Vocabulary coverage & ,125 & .02 & .41 & 5.91 & .00 \\
\hline
\end{tabular}

a. Dependent Variable: the reading comprehension level

So far, it has been discovered that the model in the regression analysis is a useful one, and this model significantly improves the ability to predict the reading comprehension levels. Therefore, the model is defined by replacing the b-values in the regression equation (Table 5): 
Table 5

The Model Predicting The Equation between The Vocabulary Coverage and Reading Comprehension

Outcome $_{i}=($ model $)+$ error $_{i}$

The comprehension level $=-7.47+(0.13 \times$ the vocabulary size $)$

For the detailed analysis, there is a need to set a reasonable comprehension as a score of understanding. For instance, Schmitt et al. (2011) define $60 \%$ comprehension as adequate, and this percentage accounts for 24 out of 40 questions. To be able to answer 24 questions, readers were expected to know 242 (83.45\%) out of 290 words in the texts used in this study. On the other hand, Laufer and Sim (1985), and Laufer (1989) determine $65-70 \%$ and $55 \%$ respectively as the minimum comprehension scores, and these percentages, for this study, correspond to 26,28 and 22 right answers respectively. If the values of 26,28 and 22 are calculated with the regression equation above, the students should know 268, 284 and 236 words out of 290 content words respectively. 268 words account for $92.41 \%$, 284 words account for $97.93 \%$, and 236 words account for $81.38 \%$ of the content words in the texts.

Based on the $70 \%$ comprehension level, Hu and Nation (2000) claim that $98 \%$ coverage is needed for adequate comprehension, and approximately the same percentages (98\%-99\% coverage) are mentioned in Schmitt et al.'s (2011) study to comprehend a text. Furthermore, Nation (2006) suggests that $98 \%$ comprehension is necessary to comprehend newspapers. The results of the present study (97.93\%) corroborate with these three studies in terms of vocabulary coverage, and it means that the model predicting the equation between the vocabulary coverage and reading comprehension can be applied to predict the vocabulary size necessary to understand the text. By using the model, it can be concluded that Turkish EFL learners at the tertiary level need to know $98 \%$ of the content words to be able to understand at least $70 \%$ of an expository text.

\section{Discussion}

Research on L2 reading has indicated that vocabulary knowledge is correlated with L2 reading comprehension (Droop \& Verhoeven, 2003; Eskey, 2005; Hu \& Nation, 2000; Pike, 1979; Qian, 2002; Schmitt, 2000; Schoonen, Hulstijn, \& Bossers, 1998; Stahl, 2003). However, the current study attempts to expand the scope of the research in terms of direct comparison of vocabulary coverage and reading comprehension. Therefore, the results are expected to offer a comprehensive description of the vocabulary coverage and reading comprehension of tertiary level Turkish EFL learners.

According to the results of the study regarding the relationship between variables, a threshold at which comprehension increases or decreases dramatically at a certain percentage of the vocabulary coverage does not appear. Instead, the correlation value 
indicates a positive moderate relationship; high numbers of the known words are associated with high scores on the comprehension test. Therefore, it can be said that there is a fairly straightforward linear relationship between the vocabulary coverage and reading comprehension of the participants. The reason for the moderate correlation might be that reading comprehension involves much more than vocabulary knowledge (Nation, 2000). To reach a deep level of comprehension, readers are required to have some skills such as inferencing, making coherent connections between ideas, scrutinizing the ideas with a critical stance, understanding the rationale of authors (Graesser, 2007), activating their background knowledge (Rumelhart, 1980) and paying attention to the social context in which texts are produced (Lantolf \& Thorne, 2007). Furthermore, readers should actively engage with a text or task to adopt a standard of coherence (Nation \& Angell, 2006; Perfetti, Landi, \& Oakhill, 2005; Schmitt et al., 2011). In other words, they should monitor their comprehension and make inferences from texts as good readers do.

Considering the results related to adequate level of comprehension (which is considered to be $70 \%$ of the text in this study), Turkish EFL readers at tertiary level need to know at least $98 \%$ of the content words in a text. Even if they know $98 \%$, they cannot comprehend the text at $100 \%$ comprehension. These two statements are in line with the findings of Hu and Nation (2000) and Schmitt et al. (2011). In this vein, it can be suggested that vocabulary knowledge is a prerequisite for comprehension. However, as Laufer (1989) pointed out, below 95\% coverage does not mean that a person cannot understand a text since some other factors are involved in the comprehension process. Even with a limited lexical knowledge, some readers might enhance their comprehension by benefiting from grammatical clues, and some readers make use of their background knowledge and their familiarity with the text type to facilitate their comprehension. On the other hand, comprehending expository texts might become a challenge for even skilled readers. The reasons behind these difficulties might be lack of knowledge in key concepts and terms, arrangement of the text, and of prior knowledge (Graesser, 2007).

\section{Implications and Conclusions}

As for the implications of the results to the curriculum developers, EFL instructors and university students, $98 \%$ coverage for academic texts and newspapers refers to the knowledge of approximately the most frequent 8000 words based on the studies of Nation (2006) and Laufer and Ravenhorst-Kalovski (2010). Therefore, Turkish EFL learners at tertiary level need to know about 8000 words to be able to read academic texts without having any problems in terms of vocabulary. In Turkey, book authors and curriculum designers should carefully examine students' needs of target vocabulary size, and they need to design vocabulary instruction accordingly. Also it can be concluded 
that scrupulously designed and aptly delivered vocabulary instruction should always be a part of language classes from the beginning of English instruction at primary education to the tertiary level. For such an instruction, corpus-informed vocabulary instruction, explicit or implicit, can be benefited as an alternative and promising methodology (Unald1, Bayrakci, Akpinar, \& Dolas, 2013). Corpus-based research might also be a starting point for teachers to determine the naturally occurring language in the classroom and focus on the unknown vocabulary or wrong usages (Vaughan, 2010) as this was emphasized in the corpus linguistics definition of Kennedy (1998, p. 1): "one source of evidence for improving descriptions of the structure and use of languages, and for various applications including the processing of natural language by machine and understanding how to learn or teach a language". Thus, teachers can improve their own awareness in both pre-service and in-service years and understand the usage of lexis in the classroom (O'keeffe, McCarthy, \& Carter, 2007). Also, they can teach students how to benefit from corpus-approaches in the classroom. Accordingly, the vocabulary knowledge of students can be increased, and, in turn, enhanced vocabulary knowledge might lead to desired levels of reading comprehension.

Considering the fact that the vocabulary size is not the only factor affecting the reading comprehension, further studies might be carried out by integrating some other factors and determinants of reading comprehension and achievement including gender, age, reading goals, topic familiarity proficiency levels (see Horiba \& Fukaya, 2015), motivation (see Dörnyei, 1994) and the use of reading strategies (see Akyel \& Ercetin, 2009; Grabe, 2009; Yayli, 2010), For instance, some vocabulary strategies such as top-down and bottom-up strategies, using linguistic clues (Kirmizi, 2014), and memory strategies (Tilfarlioglu \& Bozgeyik, 2012) seemed to be correlated with academic success in Turkish context. In sum, reading comprehension of EFL learners might be delineated by integrating different angles in a holistic way in different language settings.

\section{References}

Adamson, H. D. (1993). Academic competence, theory and classroom practice: Preparing ESL students for content courses. New York, NY: Longman.

Akyel, A., \& Ercetin, G. (2009). Hypermedia reading strategies employed by advanced learners of English. System, 37(1), 136-152.

Alderson, J. C. (2000). Assessing reading. Cambridge, UK: Cambridge.

Alderson, J. C., Clapham, C., \& Wall, D. (1995). Language test construction and evaluation. Cambridge, UK: Cambridge.

Anderson, N. (2009). ACTIVE reading: The research base for a pedagogical approach in the reading classroom. In Z. H. Han \& N. Anderson (Eds.), Second language reading: Research and instruction (pp. 117-143). Ann Arbor, MI: University of Michigan Press.

Bachman, L. F., \& Palmer, A. S. (1996). Language testing in practice: Designing and developing useful language tests. Oxford, UK: Oxford University Press. 
Bernhardt, E. B. (2011). Understanding advanced second-language reading. New York, NY: Routledge.

Bowey, J. A. (1995). Socioeconomic status differences in preschool phonological sensitivity and first-grade reading achievement. Journal of Educational Psychology, 87, 476-487.

Brown, H. D. (2003). Language assessment: Principles and classroom practices. New York, NY: Pearson.

Caravolas, M., Hulme, C., \& Snowling, M. J. (2001). The foundations of spelling ability: Evidence from a 3-year longitudinal study. Journal of Memory and Language, 45, 751-774.

Carrell, P. L., \& Grabe, W. (2002). Reading. In N. Schmitt (Ed.), An introduction to applied linguistics (pp. 233-250). Great Britain, UK: Arnold.

Cohen, J. W. (1988). Statistical power analysis for the behavioral sciences (2nd ed.). New Jersey, NJ: Lawrence Erlbaum Associates.

Collier, V. P. (1989). How long? A synthesis of research on academic achievement in a second language. TESOL Quarterly, 23(3), 509-531.

DeKeyser, R. (2007). Conclusion: The future of practice. In R. DeKeyser (Ed.), Practice in a second language (pp. 287-304). New York, NY: Cambridge University Press.

Diakidoy, I. A. N., \& Anderson, R. C. (1991). The role of contextual information in word meaning acquisition during normal reading (Center for the Study of Reading Technical Report, 531). Retrieved from https://www.ideals.illinois.edu/bitstream/handle/2142/17820/ ctrstreadtechrepv01991i00536_opt.pdf?sequence=1

Dörnyei, Z. (1994). Motivation and motivating in the foreign language classroom. The Modern Language Journal, 78(3), 273-284.

Droop, M., \& Verhoeven, L. (2003). Language proficiency and reading ability in the first and second language learners. Reading Research Quarterly, 38(1), 78-103.

Durrant, P. (2013). Formulaicity in an agglutinating language: The case of Turkish. Corpus Linguistics and Linguistic Theory, 9(1), 1-38.

Educational Testing Service. (2012). Test and score data summary for TOEFL IBT tests and TOEFL PBT tests. Retrieved from http://www.ets.org/s/toefl/pdf/94227_unlweb.pdf

Eskey, D. E. (2005). Reading in a second language. In E. Hinkel (Ed.), Handbook of research in second language teaching and learning (pp. 563-580). New Jersey, NJ: Lawrence Erlbaum.

Field, A. (2009). Discovering statistics using SPSS (3rd ed.). London, UK: Sage.

Figueroa, R. A., \& Hernandez, S. (2000). A report to the nation: Testing Hispanic students in the United States. For our nation on the fault line: Hispanic American education. President's Advisory Commission on Educational Excellence for Hispanic Americans.

Fraenkel, J. R., Wallen, N. E., \& Hyun, H. H. (2012). How to design and evaluate research in education (8th ed.). New York, NY: McGraw-Hill.

Frantzen, D. (2003). Factors affecting how second language Spanish students derive meaning from context. The Modern Language Journal, 87(2), 168-199.

Grabe, W. (2009). Reading in a second language: Moving from theory to practice. New York, NY: Cambridge University Press.

Grabe, W., \& Stoller, F. L. (2002). Teaching and researching reading. London, UK: Pearson Education Longman.

Graesser, A. C. (2007). An introduction to strategic reading comprehension. In D. S. McNamara (Ed.), Reading comprehension strategies: Theories, interventions and technologies (pp. 3-26). New York, NY: Lawrence Erlbaum Associates. 
Haastrup, K. (1991). Lexical inferencing procedures, or, talking about words: Receptive procedures in foreign language learning with special reference to English (Vol. 14). Tübingen, Germany: Gunter Narr Verlag Tübingen.

Haladyna, T. M. (2004). Developing and validating multiple-choice test items (3rd ed.). New Jersey, NJ: Lawrence Erlbaum Associates.

Horiba, Y., \& Fukaya, K. (2015). Reading and learning from L2 text: Effects of reading goal, topic familiarity, and language proficiency. Reading in a Foreign Language, 27(1), 22-46.

Hu, M., \& Nation, I. S. P. (2000). Unknown vocabulary density and reading comprehension. Reading in a Foreign Language, 23, 403-430.

International English Language Testing System. (2011). Test taker performance 2011. Retrieved from http://www.ielts.org/researchers/analysis_of_test_data/test_taker_performance_011.aspx

Kennedy, G. (1998). An introduction to corpus linguistics. London, UK: Longman.

Kirmizi, O. (2014). Measuring vocabulary learning strategy use of Turkish EFL learners in relation to academic success and vocabulary size. World Journal of Education, 4(6), 16-25.

Lantolf, J. P., \& Thorne, S. L. (2007). Sociocultural theory and second language learning. In B. VanPatten \& J. Williams (Eds.), Theories in second language acquisition: An introduction (pp. 197-221). Mahwah, NJ: Lawrence Earlbaum.

Lara, J., \& August, D. (1996). Systemic reform and limited English proficient students. Washington, DC: Council of Chief State School Officers.

Laufer, B. (1989). What percentage of text-lexis is essential for comprehension? In C. Lauren \& M. Nordman (Eds.), Special language: From humans to thinking machines (pp. 316-323). Clevedon, UK: England: Multilingual Matters.

Laufer, B. (1992). How much lexis is necessary for reading comprehension? In H. Bejoint \& P. Arnaud (Eds.), Special language: From humans thinking to thinking machines (pp. 316-323). Clevedon, UK: Multilingual Matters.

Laufer, B., \& Ravenhorst-Kalovski, G. C. (2010). Lexical threshold revisited: Lexical text coverage, learners' vocabulary size and reading comprehension. Reading in a Foreign Language, 22(1), 15-30.

Laufer, B., \& Sim, D. D. (1985). An attempt to measure the threshold of competence for reading comprehension. Foreign Language Annals, 18(5), 405-411.

Levine, A., \& Reves, T. (1998). Interplay between reading tasks, reader variables and unknown word processing. In E. Alcon \& V. Codina (Eds.), Current issues in English language methodology (pp. 119-132). Castello de la Plana, Spain: Publicacions de la Universitat Jaume.

Lewin, A., Fine, J., \& Young, L. (2001). Expository discourse: A genre-based approach to social science research texts. New York, NY: Beverly.

Linan-Thompson, S., \& Vaughn, S. (2007). Research-based methods of reading instruction for English language learners, grades $K-4$. Alexandria, VA: ASCD.

Meara, M. P. (1992). EFL vocabulary tests (2nd ed.). Swansea, UK: Lognostics.

Nation, I. S. P. (2001). Learning vocabulary in another language. Cambridge, UK: Cambridge University Press.

Nation, I. S. P. (2006). How large a vocabulary is needed for reading and listening? Canadian Modern Language Review, 63(1), 59-82.

Nation, I. S. P. (2009). Teaching ESL/EFL reading and writing. New York, NY: Routledge.

Nation, K., \& Angell, P. (2006). Learning to read and learning to comprehend. London, UK: Review of Education, 4(1), 77-87. 
O'keeffe, A., McCarthy, M., \& Carter, R. (2007). From corpus to classroom: Language use and language teaching. Cambridge, UK: Cambridge University Press.

Perfetti, C. A., Landi, N., \& Oakhill, J. (2005). The acquisition of reading comprehension skill. In M. J. Snowling \& C. Hulme (Eds.), The science of reading: A handbook (pp. 227-247). Oxford, UK: Blackwell Publishing.

Pike, L. (1979). An evaluation of alternative item formats for testing English as a second language. TOEFL (Research Reports No. 2). Princeton, NJ: Educational Testing Service.

Qian, D. D. (2002). Investigating the relationship between vocabulary knowledge and academic reading performance: An assessment perspective. Language Learning, 52(3), 513-536.

Rumelhart, D. E. (1977). Toward an interactive model of reading. In S. Dornic (Ed.), Attention and performance VI (pp. 573-603). Hillsdale, NJ: Lawrence Erlbaum Associates.

Rumelhart, D. E. (1980). Schemata: The building blocks of cognition. In R. J. Spiro, B. C. Bruce, \& W. E. Brewer (Eds.), Theoretical issues in reading comprehension (pp. 33-58). New Jersey, NJ: Lawrence Erlbaum Associates.

Schmitt, N. (2000). Vocabulary in language teaching. New York, NY: Cambridge University Press.

Schmitt, N. (2010). Researching vocabulary: A vocabulary research manual. Basingstoke, UK: Palgrave Macmillan.

Schmitt, N., Jiang, X., \& Grabe, W. (2011). The percentage of words known in a text and reading comprehension. The Modern Language Journal, 95, 26-43.

Schoonen, R., Hulstijn, J., \& Bossers, B. (1998). Metacognitive and language-specific knowledge in native and foreign language reading comprehension: An empirical study among Dutch students in grades 6, 8, and 10. Language Learning, 48, 71-106.

Stahl, S.A. (2003). Vocabulary and readability: How knowing word meanings affects comprehension. Topics in Language Disorders, 23(3), 241-247.

Stanovich, K. (1986). Matthew effects in reading: Some consequences of individual differences in the acquisition of literacy. Reading Research Quarterly, 21, 360-407.

Stanovich, K. E. (1980). Toward an interactive compensatory model of individual differences in the development of reading fluency. Reading Research Quarterly, 16, 32-71.

Stanovich, K. E. (2000). Progress in understanding reading: Scientific foundations and new frontiers. New York, NY: Guilford Press.

Thorndike, R. (1973). Reading comprehension education in 15 countries. Stockholm, Sweden: Almquist \& Wiksell.

Tilfarlioglu, F. Y., \& Bozgeyik, Y. (2012). The Relationship between vocabulary learning strategies and vocabulary proficiency of English language learners. International Journal of Applied Linguistics and English Literature, 1(2), 91-100.

Unaldi, I., Bardakci, M., Akpinar, K. D., \& Dolas, F. (2013). A comparison of contextualized, decontextualized and corpus-informed vocabulary instruction: A quasi-experimental study. Journal of Language and Literature Education, 2(8), 78-95.

Urquhart, S., \& Weir, C. (1998). Reading in a second language: Process, product and practice. New York, NY: Longman.

Vaughan, E. (2010). How can teachers use a corpus for their own research? In A. O'Keeffe \& M. McCarthy (Eds.), The Routledge handbook of corpus linguistics (pp. 471-484). London, UK: Routledge.

Walter, H. C. (2003). Reading in second language. Subject Centre for Languages, Linguistics and Area Studies Good Practice Guide. Retrieved from http://www.llas.ac.uk/resources/gpg/1420

Yayli, D. (2010). A think-aloud study: Cognitive and metacognitive reading strategies of ELT department students. Eurasian Journal of Educational Research, 38, 234-251. 
Copyright of Educational Sciences: Theory \& Practice is the property of EDAM- Education Consultancy Limited and its content may not be copied or emailed to multiple sites or posted to a listserv without the copyright holder's express written permission. However, users may print, download, or email articles for individual use. 